\title{
NUMANCIA: RELACIÓN NECRÓPOLIS-POBLADO
}

\author{
POR
}

\author{
ALFREDO JIMENO MARTÍNEZ \\ Dpto. Prehistoria. Universidad Complutense
}

\section{RESUMEN}

Este trabajo estudia la relación entre la necrópolis celtibérica y la Numancia del cerco de Escipión (133 a.C.). En la primera parte se exponen las dificultades para la localización de la necrópolis a lo largo de este siglo y los datos arqueológicos que está aportando su excavación. En la segunda se abordan los problemas estratigráficos y la dificultad de diferenciar la ciudad del 133 a.C. Finalmente se establecen las bases de relación entre necrópolis y poblado.

\section{ABSTRACT}

This paper studies the relationship between the Celtiberian cemetery and the Numancia city sieged by Scipio (133 b.C.). A first part is dedicated to present the location problems of the Celtiberian cemetery during the present century, and the archaeological data of the cemetery are also analyzed. In the second part the stratigraphic questions and the problems to differentiate the city of the II century b.C. are explained. Finally the basis is established for the relationship between the city and the cemetery.

\section{INTRODUCCIÓN}

El descubrimiento de la necrópolis celtibérica, en 1993, y su excavación a lo largo de los tres últimos años, dentro del Plan Director aprobado por la Dirección General de Patrimonio y Promoción Cultural de la Junta de Castilla y León, ha abierto nuevas perspectivas para abordar sobre nuevas bases el estudio e interpretación de Numancia, yacimiento clave para el conocimiento de la cultura celtibérica.

La necrópolis descubierta suscita una serie de preguntas previas, a las que tratamos de responder en este artículo: ¿cuál es su duración cronológica?, ¿con cuál o cuáles de las ciudades documentadas en Numancia se corresponde?, ¿qué datos tenemos para establecer esta relación?, preguntas que están directamente conectadas con uno de los problemas no resueltos en la ciudad, como es el de la estratigrafía, ya que, frente a la visión simplista de la Comisión de Excavaciones (VV.AA. 1912; Mélida 1922; Mélida et alii 1924) que contemplaba el abandono de Numancia a partir del 133 a.C. y la fundación de una ciudad romana de época augustea, tenemos la de una serie de trabajos que proporcionan una documentación más compleja, admitiendo una ocupación de Numancia a lo largo del siglo I a.C. (Wattenberg 1963a; Romero 1991: 404-432; Jimeno 1994).

Para determinar la planta de la ciudad que guarda relación con la necrópolis descubierta, además de valorar los datos estratigráficos conocidos, incorporamos una nueva información - desarrollada en otro trabajo (Jimeno y Tabernero 1996) —, extraída del estudio de las sucesivas planificaciones arquitectónicas que han dejado su huella en la planta urbanística conocida de la ciudad. Pero el establecimiento de esta concreción suscita otra pregunta: ¿dónde están las necrópolis de las otras ciudades superpuestas?

\section{BÚSQUEDA DE LA NECRÓPOLIS Y REFERENCIAS HISTÓRICAS}

Las excavaciones arqueológicas, realizadas en los inicios de este siglo, pusieron al descubierto una amplia superficie de la ciudad, pero no pudieron localizar la necrópolis, a pesar del extenso programa de sondeos (unos 53) realizados en torno al cerro numantino (Mélida y Taracena 1923:12-14). Se planteó incluso la posibilidad de que Escipión, al fortificar sus posiciones frente a Numancia, hubiera destruido la necrópolis para conseguir un efecto moral contra los sitiados (Mélida 1922: 178).

Los escritores de la Antigüedad describen un doble ritual de enterramiento entre los celtíberos; según Silio Itálico «dan sepultura en el fuego a los que mueren de enfermedad..., mas a los que pierden la vida en la guerra... los arrojan a los buitres, que estiman como animales sagrados». La ausencia de la necrópolis de incineración llevó a centrar la atención, sin bases suficientes, en unos círculos de piedra situados en la ladera sur de Numancia (próximos a la necrópolis descubierta), como el lugar idóneo para la práctica de este segundo ritual, que aparecía reflejado en algunas escenas de guerreros muertos picoteados por rapaces, representadas en las cerámicas numantinas. Estos círculos están rea- 
lizados con grandes piedras - algunas pasan de los $50 \mathrm{~cm}$ de altura - y tienen formas circulares u ovales, por lo general, con dimensiones de $3 \mathrm{~m}$ por 2,5 $\mathrm{m}$, y uno de mayor tamaño, realizado con 32 piedras, es de forma trapezoidal y mide $12 \mathrm{~m}$ de largo por $6,50 \mathrm{~m}$ de ancho, disponiendo de un suelo empedrado. Desconocemos la finalidad de estos círculos (destaca su poca homogeneidad), ya que para algunos autores pudiera tratarse de recintos sagrados o templos (Mélida 1922:174-176) e incluso de expositorio de enfermos para la cura por el sol (Iñiguez 1916); ni siquiera sabemos a qué momento corresponden, incluso cabe la posibilidad de que sean más recientes. No obstante, la aparición de la necrópolis junto a estos círculos obliga a repensar y buscar una interpretación a estas estructuras.

La ausencia de necrópolis también llevó a reparar en los restos humanos, a veces numerosos, recuperados en la ciudad (VV.AA. 1912:24-25): los de un niño inhumado, al parecer por debajo del suelo de una casa, y unas 12 localizaciones más, algunos restos formando concentraciones de más de 100 y 200 huesos, a lo largo de la calle D, una de las más largas de la ciudad. Pero estos enterramientos no tienen por qué ser de época celtibérica, ya que el cerro estuvo ocupado en sucesivos momentos, desde el Calcolítico-Edad del Bronce a la Edad Media.

Reclamaron la atención diversos cráneos completos sin maxilar inferior, conservados en algunas estancias de las casas. Destacan cuatro cráneos humanos sin maxilar inferior ni otros restos de esqueleto, documentados por Taracena al realizar trabajos de conservación, en 1940, en la manzana XXIII, que pusieron al descubierto 4 habitaciones de una casa. La ordenada con el número cuatro proporcionó dos plantas, una superior de hasta $50 \mathrm{~cm}$ de profundidad y una cueva inferior (su base se situaba a $2 \mathrm{~m}$ ) que ocupaba más de la mitad de la superficie de la planta superior. Con los cráneos aparecieron carbones de las vigas del suelo superior, vasos de cerámica (plato con orla de peces, jarra pintada, pátera con pie y biberón con círculos concéntricos) y huesos de ganado, que procedían de una habitación superior a la cueva y cayeron en ella mezclados con los escombros que la cegaron; sobre esta cueva cegada se edificó posteriormente una casa de época romana destruida en el s. II d.C. Taracena relaciona la conservación de estos cráneos con el ritual celta de las cabezas-trofeo (Taracena 1943).

A su vez, los trabajos de González Simancas sobre las fortificaciones proporcionaron dos tinajas pintadas celtibéricas de mediano tamaño con restos de huesos quemados, al parecer humanos, entre ce- nizas y tierra roja. En la misma estancia de una de ellas, casi en el centro, se encontró un excepcional monumento labrado en caliza del país con forma de sarcófago, decorado con un relieve en la cara exterior de la cabecera con una «tau», muy semejante a otras grabadas en fragmentos y vasos de cerámica numantina (González Simancas 1926: 32-33). Wattenberg, reparando en estos últimos hallazgos, indicaba que la situación de la necrópolis «es casi indudable que se encuentra en la zona norte y noreste de la población, donde excavara González Simancas», y en la que la Comisión de Excavaciones no realizó sondeos (Wattenberg 1963a:30), pero los trabajos de prospección, con apoyo de técnicas geofísicas, depararon restos y estructuras no funerarias, que hay que relacionar con establecimientos artesanales.

\section{LA NECRÓPOLIS CELTIBÉRICA}

La necrópolis se localiza en la ladera sur del cerro donde se asienta Numancia y tiene una extensión de unos 10.000 metros cuadrados. La excavación de esta necrópolis está aportando una importante información sobre la vida de los numantinos, ya que, a través del estudio de la estructura de las tumbas, los elementos de ajuar, la composición y organización del cementerio, así como de los análisis osteológicos, podemos conocer relaciones grupales y familiares y determinar la organización socio-económica (fig. 1).

\section{MORFOLOGÍA, ESTRUCTURA DE LOS ENTERRAMIENTOS Y ANÁLISIS ÓSEOS}

La necrópolis ha proporcionado, hasta ahora, 156 tumbas. El cuerpo del difunto con sus vestidos $\mathrm{y}$ adornos personales era incinerado en una pira «ustrinum» y las cenizas y restos de huesos quemados se depositaban directamente en un hoyo realizado en el suelo.

Las tumbas descubiertas ofrecen una estructura funeraria muy simple: consiste básicamente en un pequeño hoyo de dimensiones variables, limitado y protegido de forma parcial por algunas piedras, que a veces llegan a formar auténticas cajas; es frecuente la presencia de una pequeña laja de piedra hinca$\mathrm{da}$, dispuesta diferenciadamente entre las piedras que delimitan la tumba. Los restos de cremación van acompañados de ajuares y ofrendas de distinta naturaleza - predominando los adornos de bronce y las armas de hierro- y de un pequeño vaso cerámico, posiblemente de ofrendas. Algunos enterramien- 

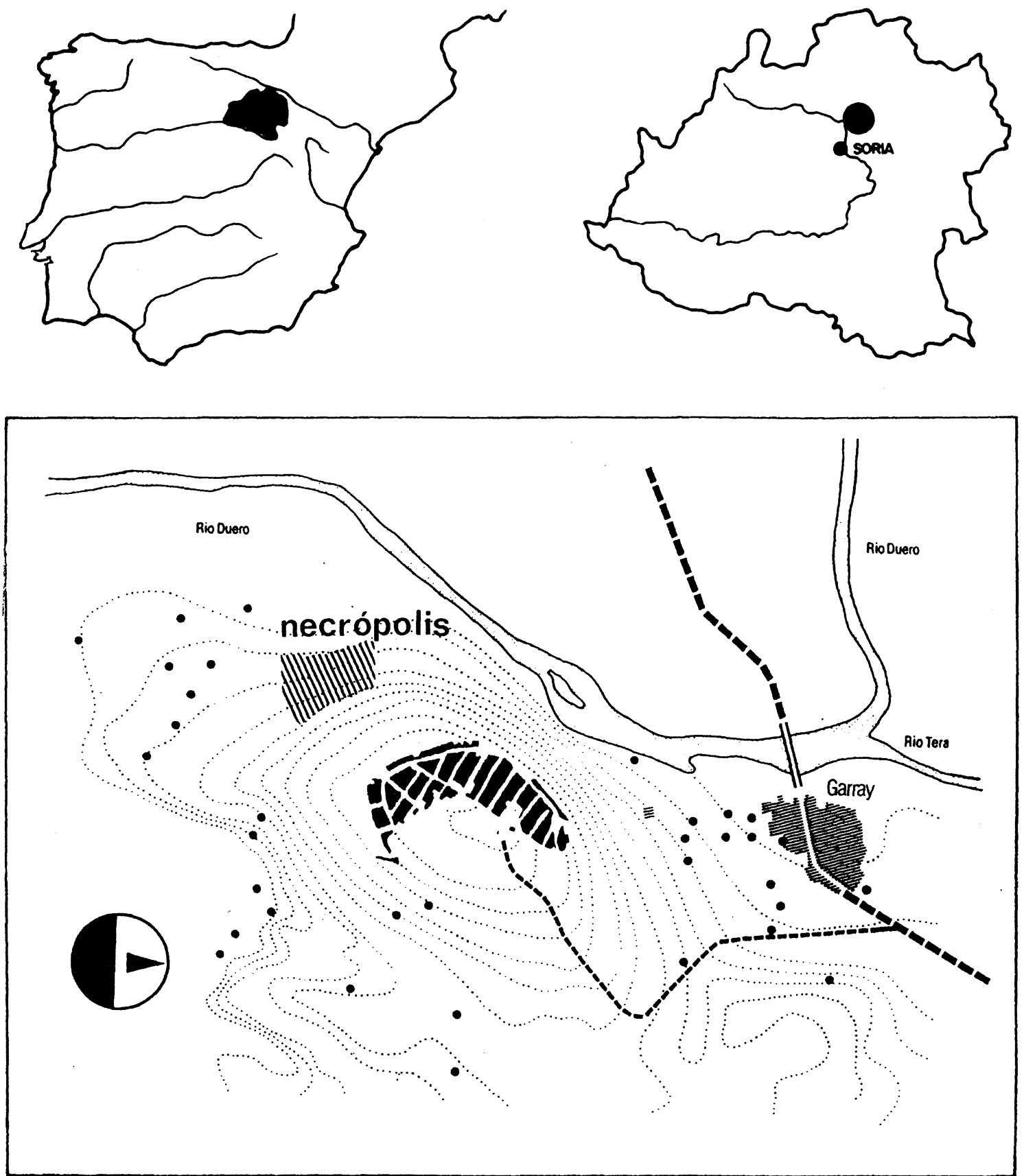

Fig. 1.-Situación de la necrópolis y de los sondeos (puntos negros) realizados a principios de siglo para su localización (según Mélida y Taracena, 1923).

tos están señalizados con estelas o piedras hincadas visibles al exterior (fig. 2).

Se están realizando análisis morfólogicos y químicos de los restos óseos quemados, a cargo del Dr. Gonzalo Trancho, del Departamento de Antropología de la Facultad de Ciencias Biológicas de la Universidad Complutense. Podemos comentar los resul- tados de los análisis practicados a los restos de 23 tumbas, que han proporcionado importantes datos para el conocimiento de aspectos relacionados con el ritual, así como con la dieta alimenticia, de la que se derivan implicaciones sociales, económicas y ambientales (Jimeno y Trancho 1996:38-39; Jimeno, Trancho et alii 1996). 


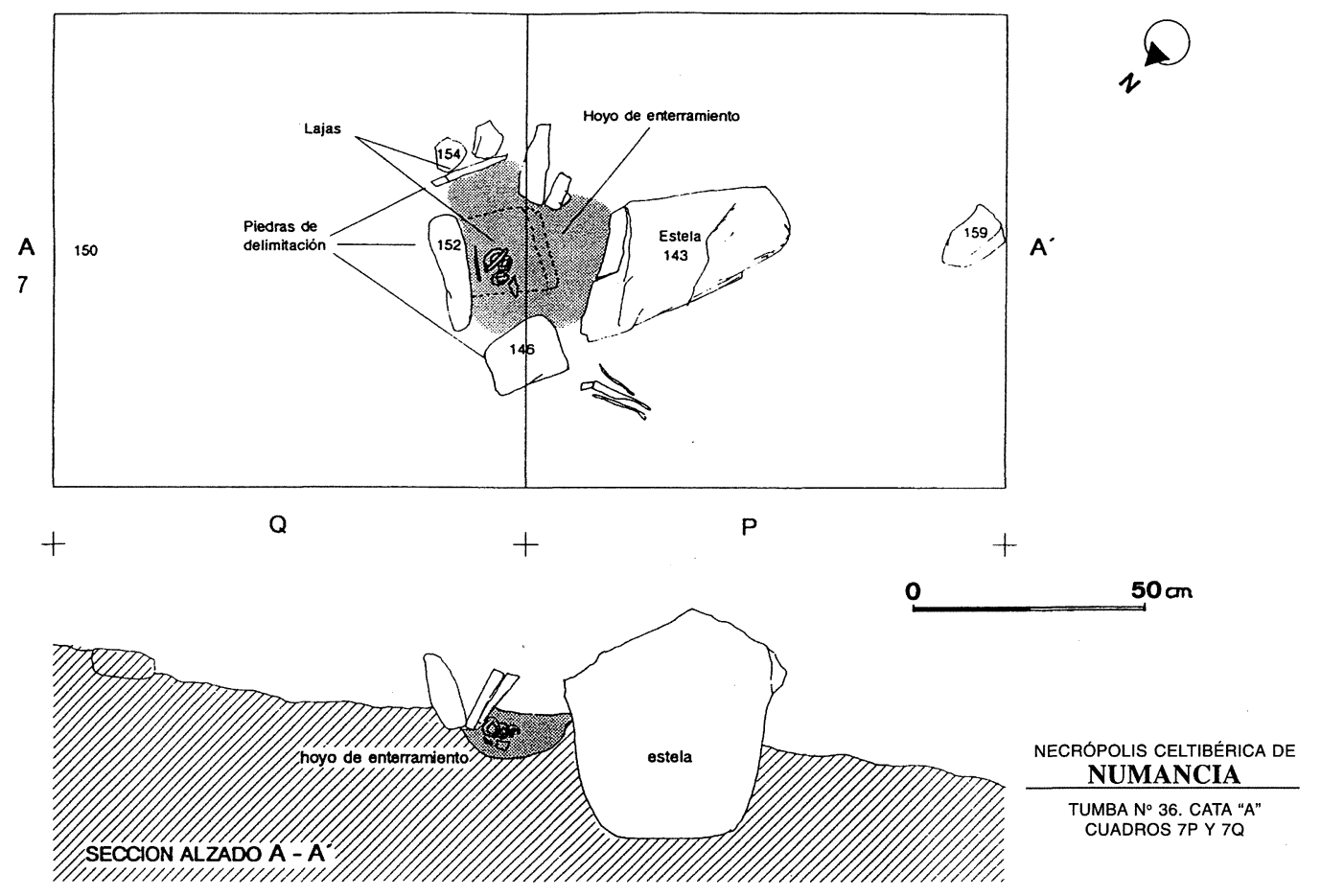

Fig. 2.-Tumba señalizada con estela. Escala 1/20.

Llama la atención la uniformidad de los restos humanos depositados en todas las tumbas, muy escasos y seleccionados - corresponden únicamente a zonas craneales y huesos largos- y fuertemente fragmentados, que hacen pensar en una acción intencionada (Gejvall 1980:484), abriendo una nueva perspectiva en la diferenciación de prácticas rituales en las necrópolis celtibéricas. Todos los huesos humanos han sido cremados a una temperatura que oscila entre 600 y 800 grados C, lo que se ha podido determinar por su coloración y contenido orgánico. Los huesos humanos corresponden únicamente a zonas craneales y huesos largos, lo que indica una selección de los huesos que se introducen en las tumbas. Es frecuente que acompañen a los restos humanos huesos de fauna, a veces cremados, correspondientes a zonas apendiculares, costillares y mandíbulas. Este ritual se conoce en otras necrópolis celtibéricas y se relaciona con porciones de carne del banquete funerario destinadas al difunto. Un porcentaje alto de tumbas $(31,8 \%)$ únicamente contiene restos de fauna, lo que hace pensar en enterramientos simbólicos, condicionados por la dificultad de recuperar el cuerpo del difunto.

Un aspecto destacado de la analítica es la determinación de la dieta alimenticia a través del análisis de oligoelementos contenidos en los restos óseos humanos. La dieta de los numantinos era rica en componentes vegetales, con un peso importante de los frutos secos (bellotas) y pobre en proteínas animales, lo que dibuja claramente las bases de su economía mixta. Pero, además, el conocimiento de la dieta de cada individuo permite relacionar su mayor o menor riqueza con las características de su ajuar y estatus, así como establecer las diferencias entre hombre y mujer.

\section{CARACTERÍSTICAS DE LOS AJUARES Y ORDENACIÓN DE LAS TUMBAS: IMPLICACIONES SOCIALES}

No podemos todavía ofrecer una información sistematizada de los 156 conjuntos funerarios descubiertos, ya que el estudio de los ajuares está en proceso de realización. Pero la composición de los conjuntos funerarios nos permite adelantar algunos aspectos diferenciales que pueden guardar relación con la estructura social de los numantinos. Las 156 tumbas se concentran en dos grandes grupos, dejando espacios intermedios con menor intensidad o sin enterramientos, que se diferencian tanto por su ubicación espacial como por las características de sus ajuares: uno ocupa la zona más alta de la ladera en 


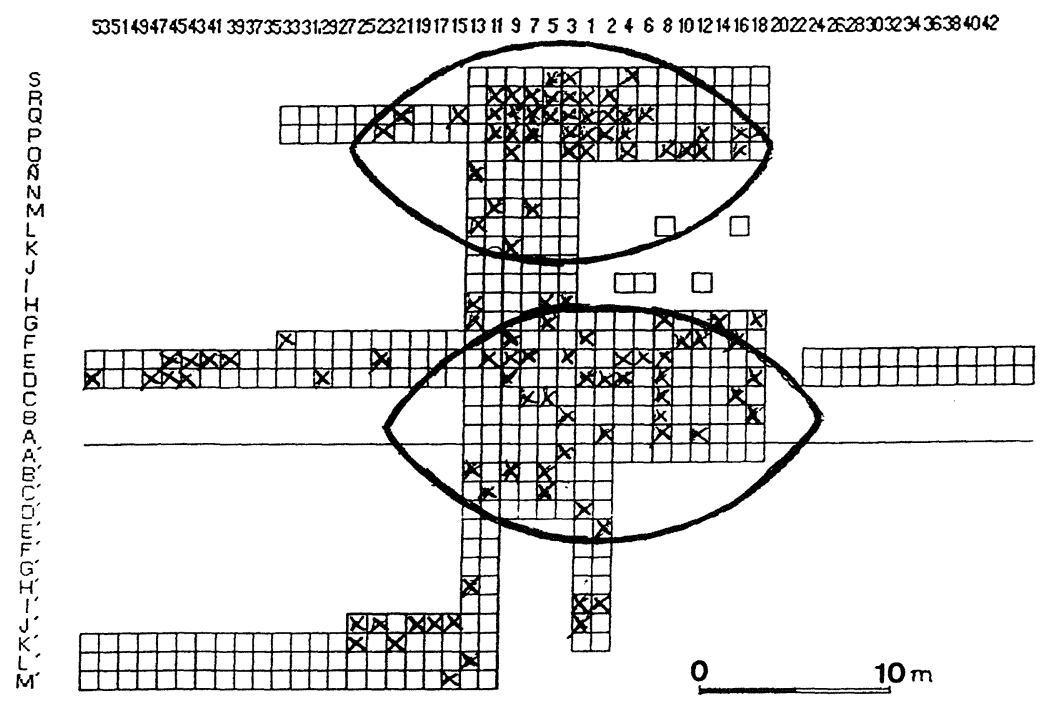

Fig. 3.-Plano de la necrópolis con los dos grupos de tumbas diferenciados. Escala 1/500.

la que se ubica la necrópolis, conteniendo sus ajuares mayoritariamente elementos de adorno y objetos de prestigio de bronce; otro grupo se sitúa en una posición más baja y está caracterizado por la presencia más generalizada de armas y objetos de hierro. Esta diferenciación estaría en función del esquema de organización social de la ciudad (fig. 3).

Hemos seleccionado un ajuar de cada uno de estos dos grupos; así la tumba 38 presenta dos báculos de distinción o estandartes $(10,6 \mathrm{~cm}$ de alto $\mathrm{x}$ $7,2 \mathrm{~cm}$ de ancho), decorados con dos prótomos de caballo, unidos por la grupa y montados por un jinete; el cuerpo de los animales está decorado con círculos concéntricos, siendo de mayor tamaño los dispuestos sobre las ancas; dos cabezas humanas se sitúan debajo de las cabezas de los caballos y otras dos ocupan el sitio de las patas; en este lugar confluyen los dos extremos de una horquilla en un elemento tubular inferior, de $3 \mathrm{~cm}$ de diámetro, que servía para encajarlos en sendos vástagos o astiles de madera, que iban protegidos en su parte inferior con conteras de hierro, también localizadas en el conjunto (fig. 4). Se conoce otro estandarte similar procedente de la ciudad, que fue hallado por la $\mathrm{Co}-$ misión de Excavaciones en Numancia en 1923, aunque ha desaparecido del Museo Numantino (Mélida et alii 1924:30), y posteriormente recogido por Schulten (1931:271; Lorrio 1994:239), lo que ha dado pie para interpretarlo como procedente de sus excavaciones. Acompañan a estas excepcionales piezas una placa de cinturón rectangular de es- cotaduras cerradas (conservando el macho y la hembra) y bella decoración geométrica, cuatro fíbulas del tipo anular y de pie vuelto y otros fragmentos de fíbulas no identificables; así como unas

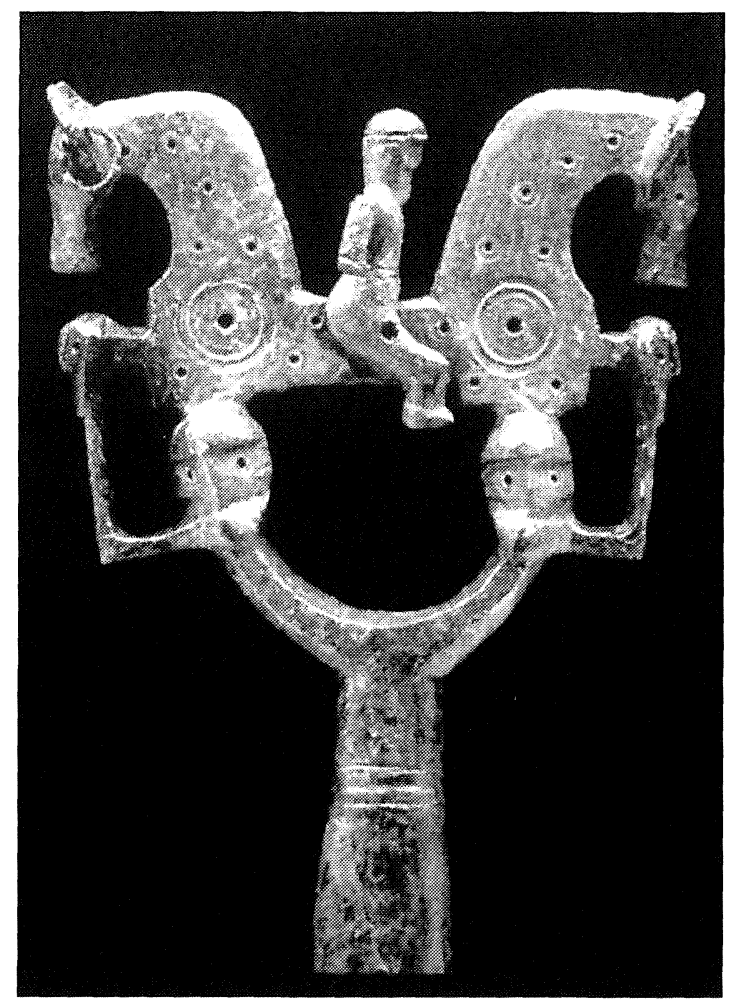

Fig. 4.-Báculo de distinción o estandarte de la tumba 38. 
nueve agujas de bronce muy fragmentadas, un resto de alambre serpentiforme correspondiente a algún adorno, varillas y restos de hierro no reconocibles.

En el conjunto 32, sustituyendo la figura del báculo de distinción o estandarte, parece estar una fíbula de bronce cuyo motivo decorativo lo constituye un caballo con jinete tocado con casco; finas incisiones paralelas señalan las riendas en el ollar y otras más finas decoran las zonas del cuello, círculos concéntricos configuran los ojos y decoran los cuartos delanteros y traseros del animal y pequeñas anillas se insertan en la crinera y la cola, para propiciar su tintineo con el movimiento (Jimeno 1994:56). Al menos se reconocen otras siete variantes de ajuares a base de la combinación de placas de cinturón y fíbulas con agujas, varillas, cuentas de pasta vítrea y la presencia de pequeños vasos de cerámica.

El conjunto 2 es fiel exponente del segundo grupo con armas. Lo componen dos puñales de frontón de hierro, uno sumamente doblado para su inutilización, dos fíbulas de bronce con disco decorado, una punta de lanza doblada y un pequeño cuchillo de hierro (fig. 5). Se pueden establecer al menos ocho variantes de ajuar con algún elemento armamentístico (espadas, puñales, lanza, umbo de escudo, cuchillo), bocado de caballo, tijeras, fíbulas, placa de cinturón, presillas, canicas y cuentas de pasta vítrea y conteniendo un número muy variable de objetos, desde las que ofrecen unos 14 elementos a las que tienen 2 solamente.

Se practica en esta necrópolis de forma generalizada, al igual que en otras celtibéricas, la inutilización intencionada de todas las armas y objetos de metal (fig. 5). Las armas aparecen fuertemente dobladas, así como los objetos de adorno realizados sobre chapa; las fíbulas aparecen completas, pero siempre tienen forzados los resortes; a su vez muchos de los objetos de metal recuperados, como las fíbulas y los broches de cinturón, muestran señales evidentes de haber sido incinerados acompañando al difunto. Esta práctica trataba de evitar la separación del difunto de sus objetos personales, ya que existía una completa identificación entre la persona y éstos (las armas para el guerrero) como exponentes visibles de su propia identidad. Los objetos eran «matados» a modo de sacrificio, con el fin de acompañar a su difunto portador para siempre (Sopeña 1987:85); también existen referencias etnográficas de la necesidad de la muerte ritual, la destrucción íntegra del objeto o el arma, para que su espíritu pueda acompañar al difunto al Más Allá (Reverte 1990:334).

\section{CRONOLOGÍA DE LAS TUMBAS EXCAVADAS}

Las fíbulas, por su diversidad y frecuencia en el conjunto de la necrópolis, nos proporcionan una referencia para poder determinar su cronología global. Hemos ajustado la clasificación tipológica de las fíbulas halladas en la necrópolis a la de Argente (1994), matizada por la de Cabré y Morán (1979 y 1982), aunque no estamos de acuerdo con dicha clasificación, para poder establecer la comparación con la ordenación de las fíbulas de la ciudad realizada por este autor. Los 156 conjuntos funerarios localizados hasta ahora aportan 151 fíbulas reconocibles -no se contabilizan las aparecidas fuera de las tumbas-; todas ellas son de bronce, a excepción de 6 realizadas en hierro. Los conjuntos funerarios que contienen fíbulas son 71 , siendo las más abundantes las de pie vuelto (69 ejemplares, 45,69\%), seguidas de las anulares (45 ejemplares, $29,80 \%$ ); en menor proporción están las simétricas ( 9 ejemplares, 5,9\%), las de torrecilla (7 ejemplares, 4,63\%), La Tène II (3 ejemplares, 1,98\%), La Tène IIIII A - Grupo IV de Cabré-Morán (1979:10)(3 ejemplares, $1,98 \%$ ), las de pie vuelto rematado en disco (5 circular y 1 cuadrado, 3,97\%), las de caballito ( 2 ejemplares, una con jinete, $1,32 \%$ ); con un solo ejemplar están representados otros tipos zoomorfos, una de pie zoomorfo en «S» y posible alfiler-fíbula (fig. 6).

El tipo de fíbula de pie vuelto está representado -él solo- en 23 conjuntos y en otros 15 va asociado a otras fíbulas; el tipo anular aparece -él soloen 13 conjuntos y acompaña a otras fíbulas en 15 tumbas; los tipos de torrecilla aparecen solos en 3 de los 7 ajuares con armas en los que están presentes; finalmente, los de pie rematado en disco o cazoleta con doble vástago de unión con el puente aparecen solos en 4 ocasiones y en asociación solamente en una. La relación de estas fíbulas en una misma tumba - se conocen asociaciones en 21 tumbas-ofrece diferentes modalidades; así en 14 ocasiones encontramos juntos dos tipos: anulares-pie vuelto (en 7 ocasiones), pie vuelto-simétricas (en 2 ocasiones), pie vuelto-torrecilla (en 2 ocasiones), anular-torrecilla (en 2 ocasiones), pie vuelto-pie zoomorfo en «S» (en 1 ocasión), anular-torrecilla (en 1 ocasión) y pie vertical rematado en disco-simétrica (en 1 ocasión). La asociación de tres tipos se observa en dos conjuntos: en uno anular-pie vuelto-caballito y en el otro anular-pie vuelto-La Tène II. La asociación de cuatro elementos se documenta también en otros dos conjuntos: en uno anular-pie con disco cuadrado-pie vuelto-caballito y en otro anular-simétrica-torrecillaLa Tène II; finalmente un solo conjunto en donde se 


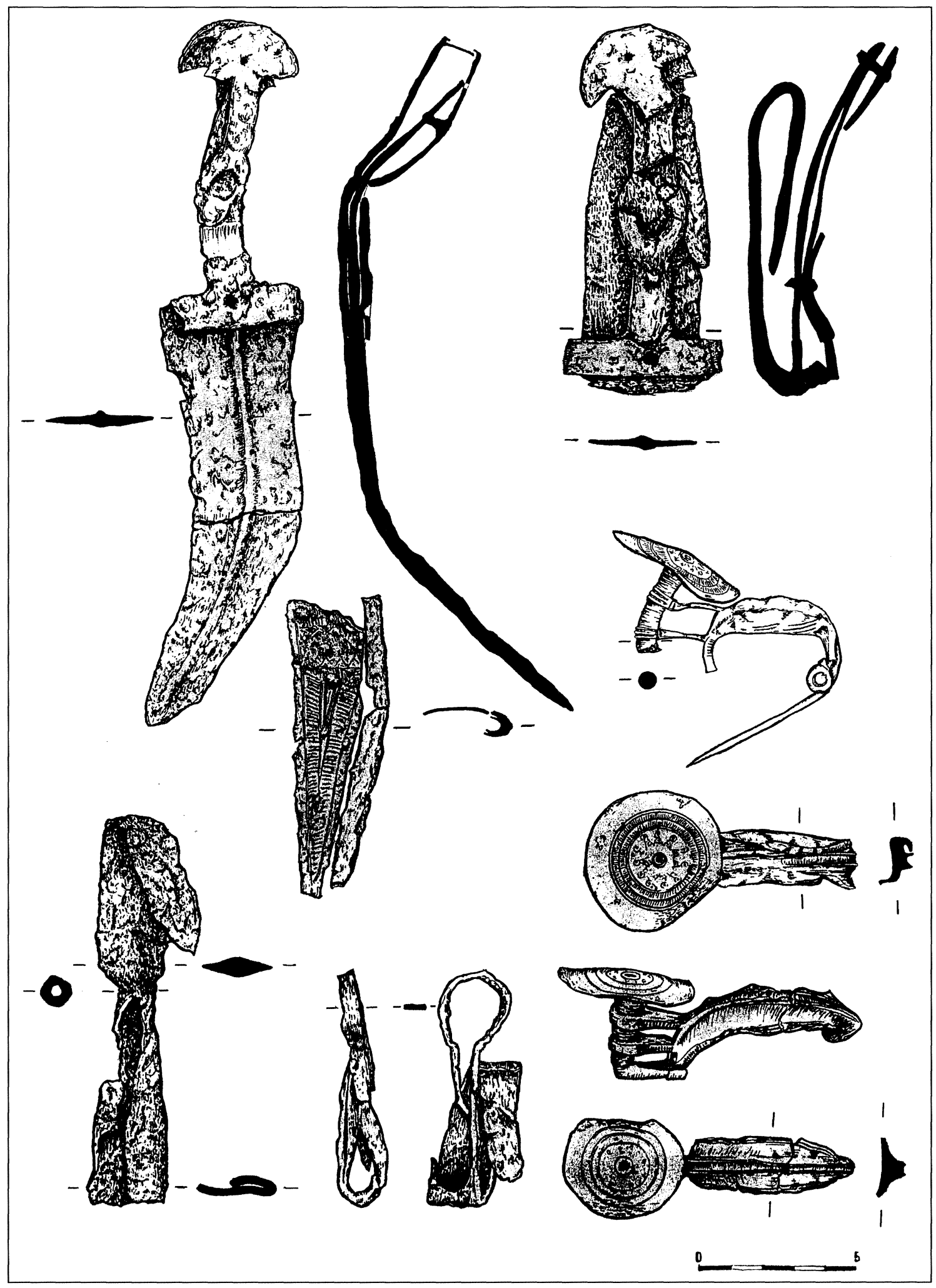

Fig. 5.-Ajuar con armas de la tumba 2. Escala 1/2. 


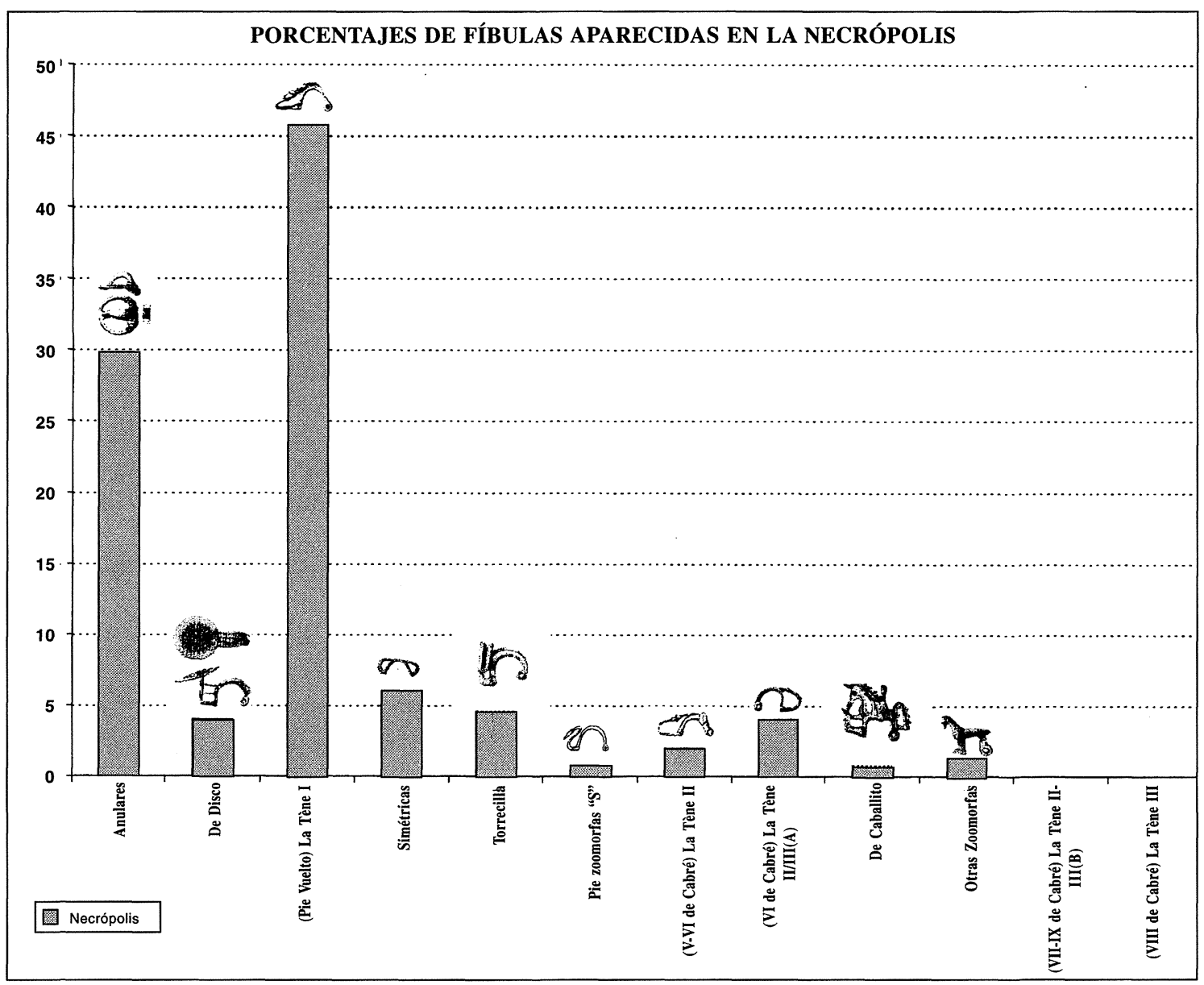

Fig. 6.-Representación de los diferentes tipos de fíbulas de la necrópolis.

asocian cinco tipos: anular, pie vuelto, simétrica, La Tène II-III A y alfiler-fíbula (fig. 7).

Por otro lado, la asociación de puñal de frontón, espada meseteña de imitación de La Tène, buena representación de las puntas de lanza (Cabré 1990:220; García Soto-Mateos 1990:34) y fíbulas de disco y cazoleta (fase B2 de Schüle y tipo 7D de Argente) de cabecera perforada y doble vástago de unión del pie con el puente (copia de modelos laténicos avanzados), permite pensar en un marco cronológico a partir del 300 (Schüle 1969:143, 149; Cabré 1990:220; Cabré y Morán 1979:109; Argente 1994:78-83; Argente y Romero 1990:133-134) y que concretamos en la segunda mitad del siglo III a.C. e incluso la mitad del siglo II a.C. Otras tumbas próximas a estos conjuntos muestran fíbulas de La Tène II, que apuntan a este momento más reciente, como se ha documentado entre los pueblos célticos del Suroeste (Berrocal 1992: 137). En este sentido, también conviene recordar el ajuar número 13 de la necrópolis de Uxama, en donde una fíbula de
La Tène III se asocia a un puñal de frontón y una espada de imitación de La Tène, que lleva a fecharlo en la primera mitad del siglo II a.C. (Cabré 1990:218; García-Soto 1990:34).

Las referencias cronológicas de la necrópolis permiten relacionarla con la ciudad celtibérica de Numancia, destruida por Escipión en el 133 a.C., por lo que a continuación analizamos los problemas estratigráficos y las referencias arqueológicas existentes para poder identificar esta ciudad en el cerro de La Muela.

\section{ESTRATIGRAFÍA Y SUPERPOSICIÓN DE CIUDADES EN NUMANCIA}

No contamos con noticias y documentación arqueológicas precisas que nos permitan señalar con exactitud el momento del surgimiento de las ciudades celtibéricas; sabemos de su existencia en los inicios de la conquista pero desconocemos la anti- 


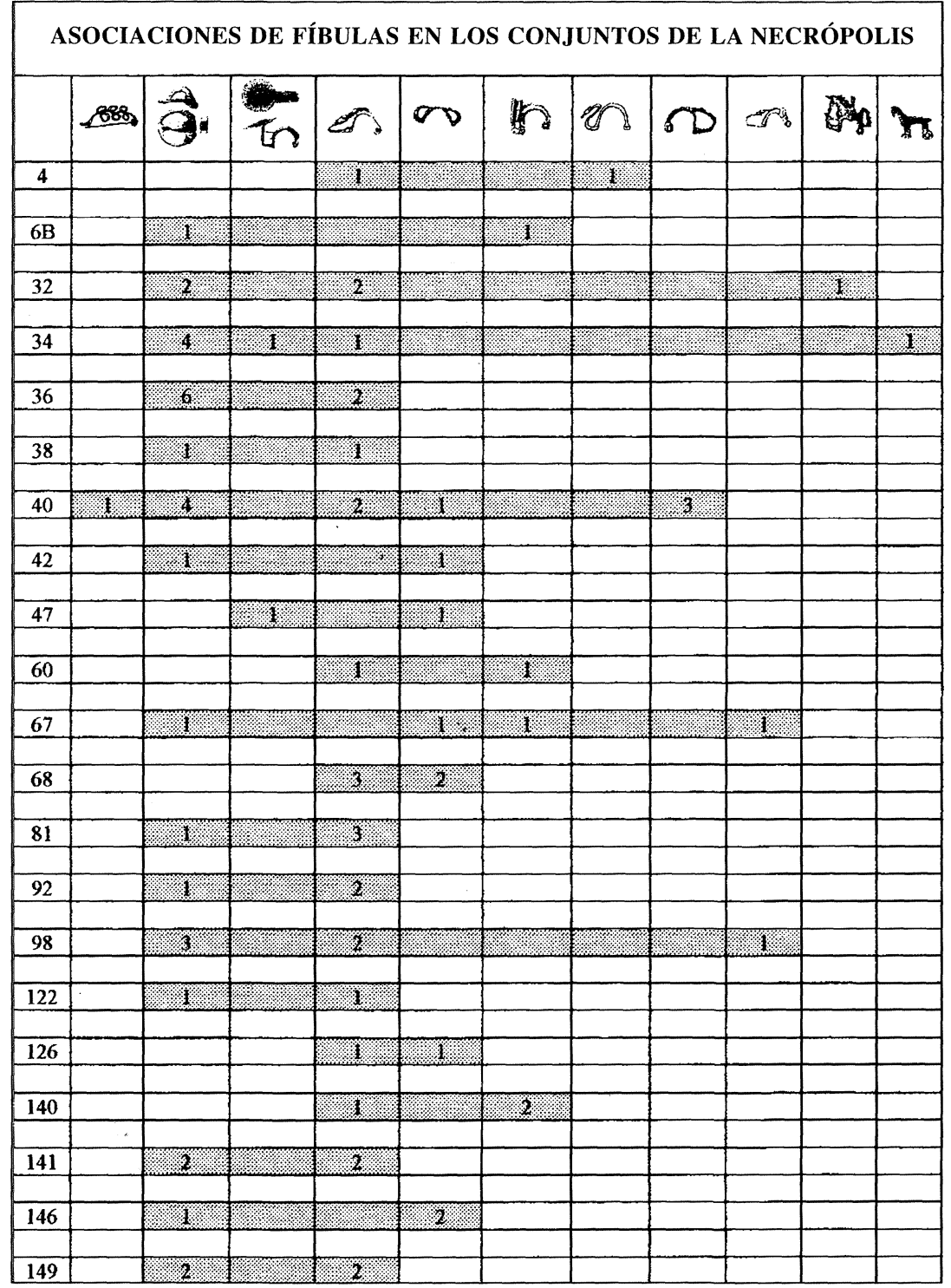

Fig. 7.-Diferentes asociaciones de fíbulas en las tumbas.

güedad de su origen. No obstante, la valoración de diferentes noticias sobre algunas ciudades nos lleva a admitir para el desarrollo del urbanismo un momento tardío y sólo ligeramente anterior al inicio de la conquista romana e, incluso, para algunos aspectos de dinamización de este fenómeno, como la escritura y la moneda, una etapa ya bajo control romano. Todo ello nos ha llevado a plantear para la fundación de Numancia un momento poco preciso de inicios del siglo II a.C. (Jimeno 1994; Jimeno y Morales 1993; Jimeno y Arlegui 1995).

Dejando aparte los restos dispersos de época prehistórica (del Eneolítico-Bronce e inicios de la
Edad del Hierro), así como los restos más recientes de época visigoda y medieval, las excavaciones de principios de siglo, llevadas a cabo por la Comisión de Excavaciones nombrada por el Ministerio de Instrucción Pública, diferenciaron dos ciudades, una más antigua celtibérica, que no podía ser otra que la heroica Numancia del 133 a.C., sepultada por un «sudario» de incendio y destrucción, que la separaba de otra romana posterior atribuida a Augusto, superpuesta y acomodada en gran medida al trazado de la anterior (VV.AA 1912:10; Mélida 1922; Mélida et al. 1924; Taracena 1941:70-71).

La amplia superficie excavada por la Comisión 


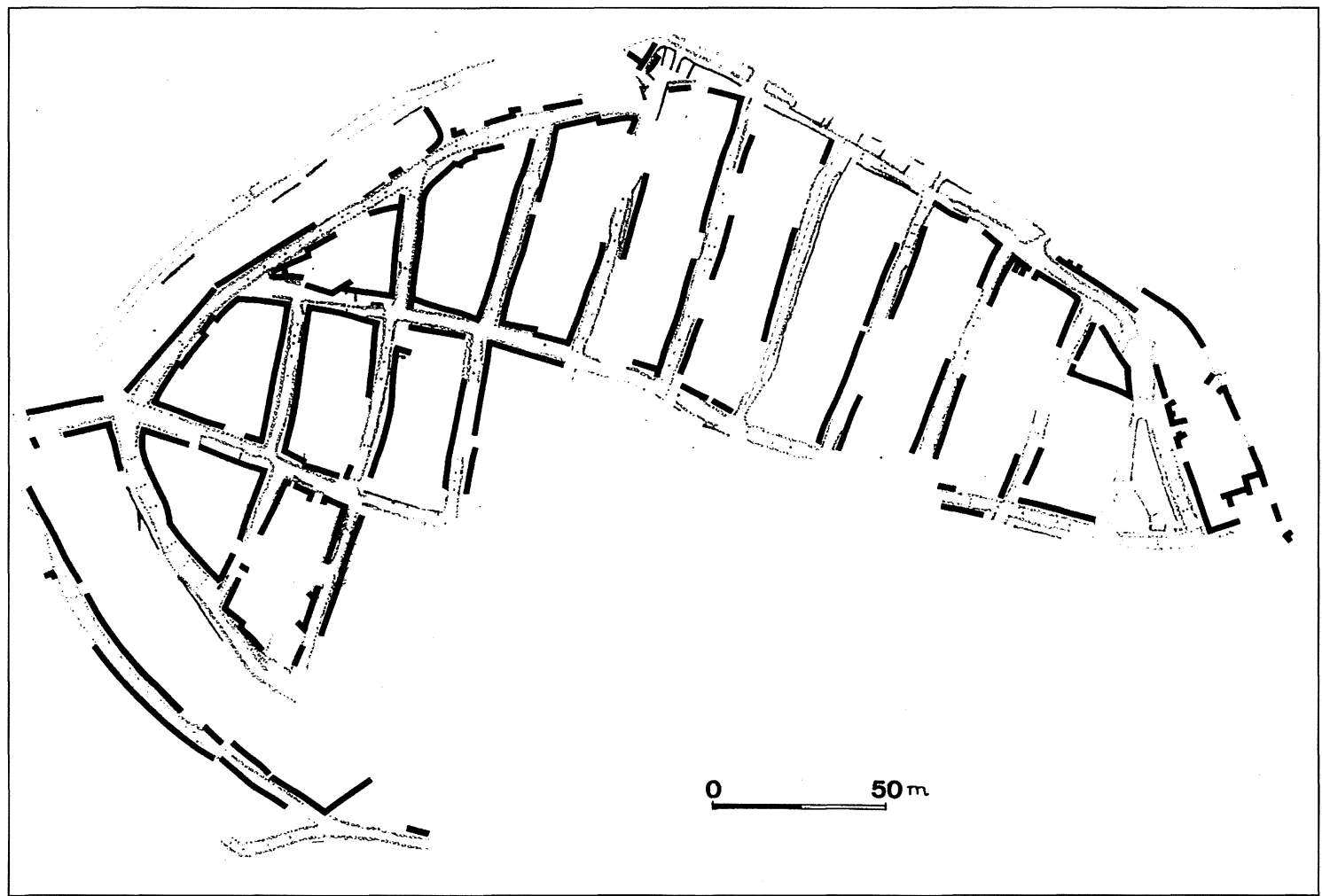

Fig. 8.-Planta urbana y superposición de ciudades: en línea negra gruesa la romana y en línea más fina la celtibérica (Taracena 1941). Escala 1/2.500.

puso al descubierto la planta urbana de las dos ciudades, constituidas por algo más de diecinueve calles y veinte manzanas, que permiten conocer su trazado y organización en torno a dos largas calles paralelas de ejes Nordeste-Sudoeste, cruzadas por otras once también paralelas de dirección Este-Oeste - mayor número de calles en esta dirección contraria al viento norte dominante-, formando una retícula uniforme, sin dejar espacios libres o plazas, pero los encuentros de las calles son escalonados para evitar las corrientes de aire. Esta cuadrícula, con el centro ligeramente desplazado hacia el Oeste de la meseta, queda envuelta al Occidente por una calle semicircular paralela a la muralla que por el sur dobla pronto, internándose en la ciudad, y tiene todavía en esta dirección otras tres calles paralelas que parecen formar nuevos anillos concéntricos exteriores (fig. 8).

Un cerco murado se conoce en el cuadrante Noroeste y en un pequeño tramo del Nordeste. En esta última zona es de sección trapezoidal, de $3,40 \mathrm{~m}$ de anchura en la base, formado con cantos rodados sin carear, conservado con dos metros de altura, precedido de un pequeño antemuro y con viviendas adosadas al interior, como en todos los poblados celti- béricos. En el Noroeste tiene los mismos materiales y sección, pero es de espesor muy desigual y va aislado por una estrecha calle de ronda. Sólo se han descubierto hasta ahora dos puertas de acceso a la ciudad, ambas en el cuadrante Noroeste y formadas por una simple interrupción del muro.

Las calles son de empedrado de canto irregular, con aceras de grandes cantos rodados y dotadas de piedras pasaderas a intervalos regulares para cruzar el arroyo. Las manzanas rectangulares y las viviendas yuxtapuestas, de múltiples formas, corresponden mayoritariamente a época imperial romana; no obstante, el trazado de la ciudad inferior, al que se ajusta la superior, queda evidente en los arroyos de las calles, descubiertos por debajo de los de la ciudad superpuesta, y en alguna zona de casas rectangulares de tipo celtibérico. Las casas de la ciudad infrapuesta son de zócalos de mampostería seca, de canto de río sin carear y elevación de cestería de ramas manteada de barro; las divisiones interiores son generalmente de adobe y las cubiertas debieron ser de ramaje y tierra. Por lo general, tienen bajo la habitación de entrada una cueva o bodega, de entre 1,50 a $2 \mathrm{~m}$ de profundidad, donde se guardaban los alimentos. Las casas de la ciudad romana superior son de pie- 
dra con cubierta vegetal y de mayores dimensiones y complejidad funcional, también con estancias subterráneas (Mélida 1922; Mélida et alii 1924; Taracena 1941; Ortego 1967; Jimeno et alii 1990).

Esta visión «oficial» asumía un dilatado período de tiempo, un siglo, durante el cual Numancia estuvo desocupada. Frente a esta interpretación, los trabajos de Schulten, que se desarrollaron en la ciudad un año antes de los de la Comisión, muestran una mayor complejidad estratigráfica y superposiciones arquitectónicas no anotadas en el plano de la ciudad elaborado por la Comisión de Excavaciones. Los trabajos del investigador alemán realizados en la manzana IV documentaron tres niveles que denominó «ibérico», «iberorromano» y «romano» (Schulten 1914:12-17), relacionados con estructuras superpuestas correspondientes a tres ciudades: una superior con construcciones más complejas y bien documentadas de época augustea; otra inferior, relacionada con la del 133 a.C., con casas rectangulares (con distribución tripartita de su espacio y bodega) apoyadas en la muralla; otra intermedia sobre los restos numantinos, también con casas rectangulares, como las de la ciudad anterior, pero con orientación distinta (fig. 9). Se podría, pues, suponer, decía Schulten, que a partir del año 133 a.C., «a algunos iberos comarcanos, tal vez los que recibieron las tierras de los numantinos, les fue permitido es- tablecerse en las ruinas». Este pequeño establecimiento desapareció luego al levantarse la ciudad romana (Schulten 1945:255).

Esta mayor complejidad estratigráfica queda reflejada sobre todo en los trabajos de González Simancas, miembro de la Comisión de Excavaciones que se encargó de documentar el sistema defensivo de la ciudad, quien, alejándose de la interpretación «oficial», llama la atención sobre la existencia de más de un nivel de incendio, diferenciando una muralla pre-escipiónica, dos ciudades incendiadas celtibéricas, una ciudad romana imperial y otra del Bajo Imperio (González 1926:39), pero estas observaciones no serán tenidas en cuenta (Romero 1991:405).

Serán los trabajos de Wattenberg (1960, 1963a y 1963b) los que incidan sobre lo apuntado por González Simancas, reinterpretando a su vez las estratigrafías proporcionadas por Könen (arqueólogo que trabajó con Schulten). Wattenberg atenderá cuidadosamente y entresacará de los textos clásicos aquellos momentos en los que Numancia se vio involucrada en conflictos bélicos y supuestamente destruida, relacionando los tres niveles de incendio que ofrecen estas estratigrafías con otros tantos momentos históricos, que relaciona con el 133 —el más potente-, uno segundo que sitúa entre el 133 y el 75 a. C. y el tercero entre este año y el 29 a.C., con
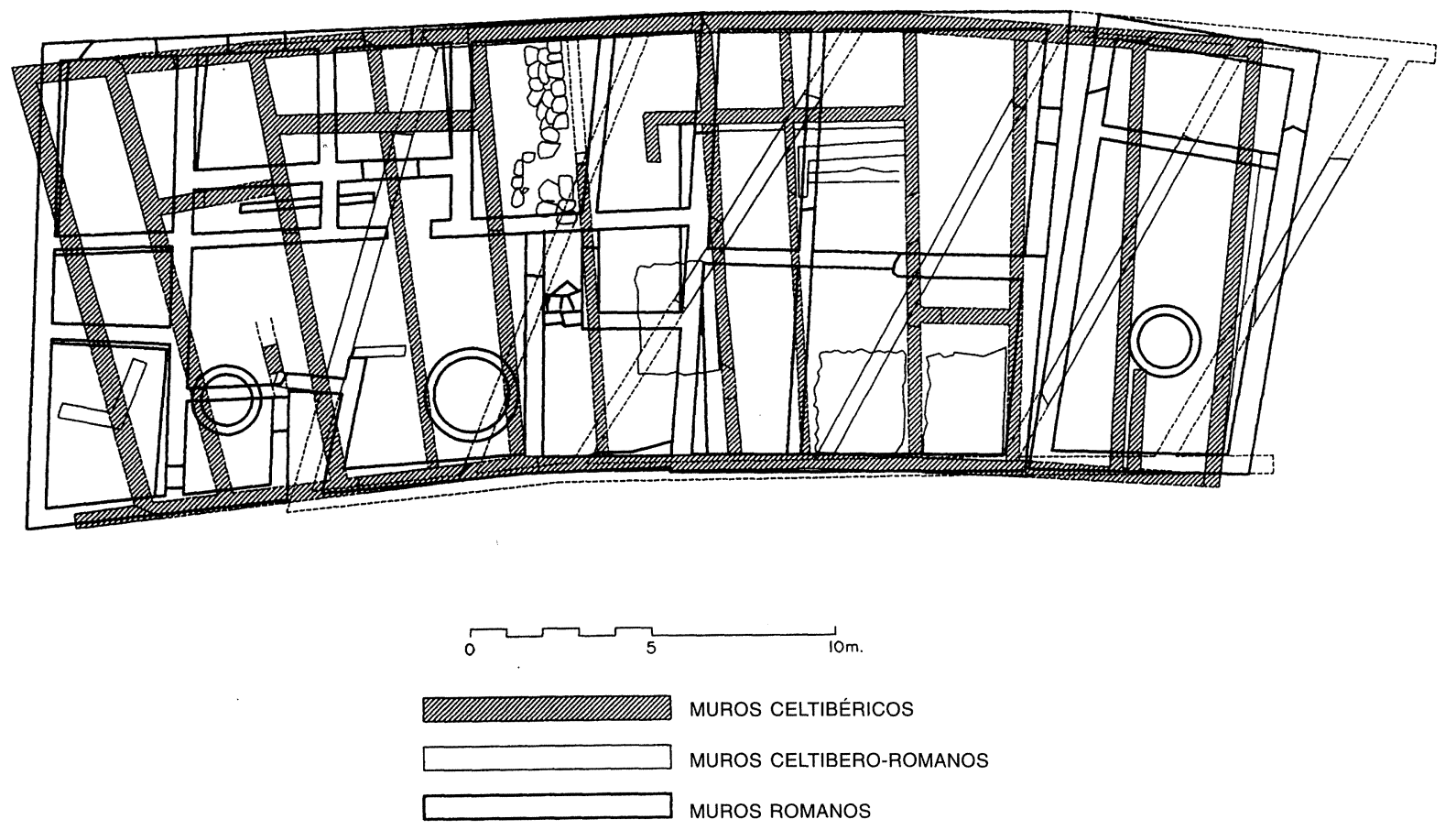

Fig. 9.- Superposición de casas en la manzana IV (según Schulten). Escala 1/250. 
el inicio de las campañas contra vacceos, cántabros y astures (1963a:20-22). Para Wattenberg, las dos plantas de ciudades - consideradas celtibérica y romana-, recogidas en el plano clásico de Taracena, serían posteriores al 133 a.C. y su urbanismo se explicaría por ser obra romana; trazado que se conservó y aprovechó posteriormente en época imperial.

Esta interpretación estratigráfica es acorde con la nueva ordenación que Wattenberg estableció para las cerámicas numantinas, tanto monócromas como polícromas, a lo largo del siglo I a.C., afirmada por trabajos posteriores que han establecido relaciones entre la iconografía numantina y las acuñaciones monetarias indígenas, manteniendo la idea de que la figura humana se incorpora al repertorio iconográfico numantino, al igual que algunos otros elementos, bajo la influencia romana e, incluso, prolongándose las polícromas a los inicios del Imperio (Wattenberg 1963a; Romero 1976:177-189). Pero, a su vez, este esquema tiene también algunos puntos débiles. En primer lugar, todas las conclusiones estratigráficas se deducen de cortes practicados en una superficie reducida de la ciudad; ofrece una visión de la ocupación de Numancia continuista, sin interrupciones, desde la base indígena más antigua hasta la época imperial romana; finalmente, resulta evidente en esta interpretación el dirigismo que ejercen los acontecimientos bélicos acaecidos en la Celtiberia, narrados en las fuentes, y es problemático que éstos queden reflejados tan minuciosamente en una parte reducida de la ciudad. En el futuro, la valoración de estos trabajos habrá que hacerla a la luz de los datos estratigráficos del cerro en su totalidad.

Estos trabajos coinciden, frente a los «oficiales» de la Comisión, en la observación de una mayor complejidad estratigráfica y la existencia de una o más de una ciudad a lo largo del siglo i a. C., con anterioridad a la de época imperial romana. Ante esta perspectiva, el hallazgo de la necrópolis de incineración plantea el problema de determinar si corresponde a la ciudad destruida en el 133 a.C. o al poblamiento celtibérico, que indudablemente existió a lo largo del siglo I a.C., o si pudo ser utilizada con anterioridad a la famosa destrucción y continuar en uso en época posterior.

\section{LA HUELLA DE LAS SUCESIVAS CIUDADES SOBRE EL PLANO DE LA CIUDAD}

El análisis de la planta visible de la ciudad, a través de los planos y fotografías aéreas disponibles, tanto antiguos como modernos, nos ha permitido diferenciar aquellas líneas e irregularidades que se apartan del trazado armónico de la urbanística conocida y que creemos que son huella de los sucesivos trazados urbanos que se sucedieron en el cerro de la Muela de Garray. Al conocimiento de la urbanística y de la información aportada por las excavaciones hay que añadir los datos proporcionados por la fotografía aérea, a través de diferentes vuelos, antiguos y modernos, en blanco y negro, color e infrarrojos. El conjunto de toda esta información nos ha proporcionado referencias para determinar diferentes configuraciones urbanas que deben de corresponder a distintas ciudades y/o ampliaciones de recintos urbanos inicialmente más pequeños.

La zona sur es la que ofrece una mayor información a la hora de analizar los sucesivos planeamientos urbanísticos. Se observa uno interior, más antiguo, de forma semicircular, a partir del cual se ajustaron las diferentes ampliaciones y/o ciudades posteriores. La ordenación semicircular vendría impuesta tanto por las características de la pendiente, como por la existencia de un cierre murado con ese geometrismo en esta zona, ya desde la ciudad celtibérica más antigua. De esta manera hemos podido diferenciar recintos y estructuras urbanas correspondientes a la ciudad del 133 a.C., del siglo r a.C., de época imperial romana y el cerco amurallado bajoimperial, que nos permiten ahora poder relacionar con la necrópolis descubierta (fig. 10).

\section{EL TRAZADO DE LA CIUDAD DEL 133 A.C.}

Esta ciudad la conocemos muy mal arqueológicamente pero las escasas referencias que podemos manejar nos permiten ponerla en relación con la necrópolis descubierta. Apiano y Orosio indican que el perímetro de la ciudad era de 24 estadios (185 m por estadio) y 3.000 pasos respectivamente, que equivalen aproximadamente a unas 150 ha (Mélida 1922:170), lo que no responde a la realidad de la topografía y la documentación arqueológica. Schulten $(1914,1945,1957)$, ajustándose al texto de Apiano, imaginaba Numancia sin defensa exterior, alcanzando un total de 93 hectáreas para acoger a los pueblos refugiados y coronada por una acrópolis de 7,2 hectáreas. Esta interpretación fue compartida en general (Mélida 1922:173), pero Taracena planteó objeciones a esta explicación de Schulten por no encontrar contrastación arqueológica y consideró que la ciudad compacta y murada era mucho mayor de 7,2 hectáreas, alcanzando una superficie intramuros de unas 22 hectáreas ó 24 si se incluye el arrabal de Saledilla, siendo la mayor del territorio arévaco (Taracena 1941:71). Los cálculos actua- 


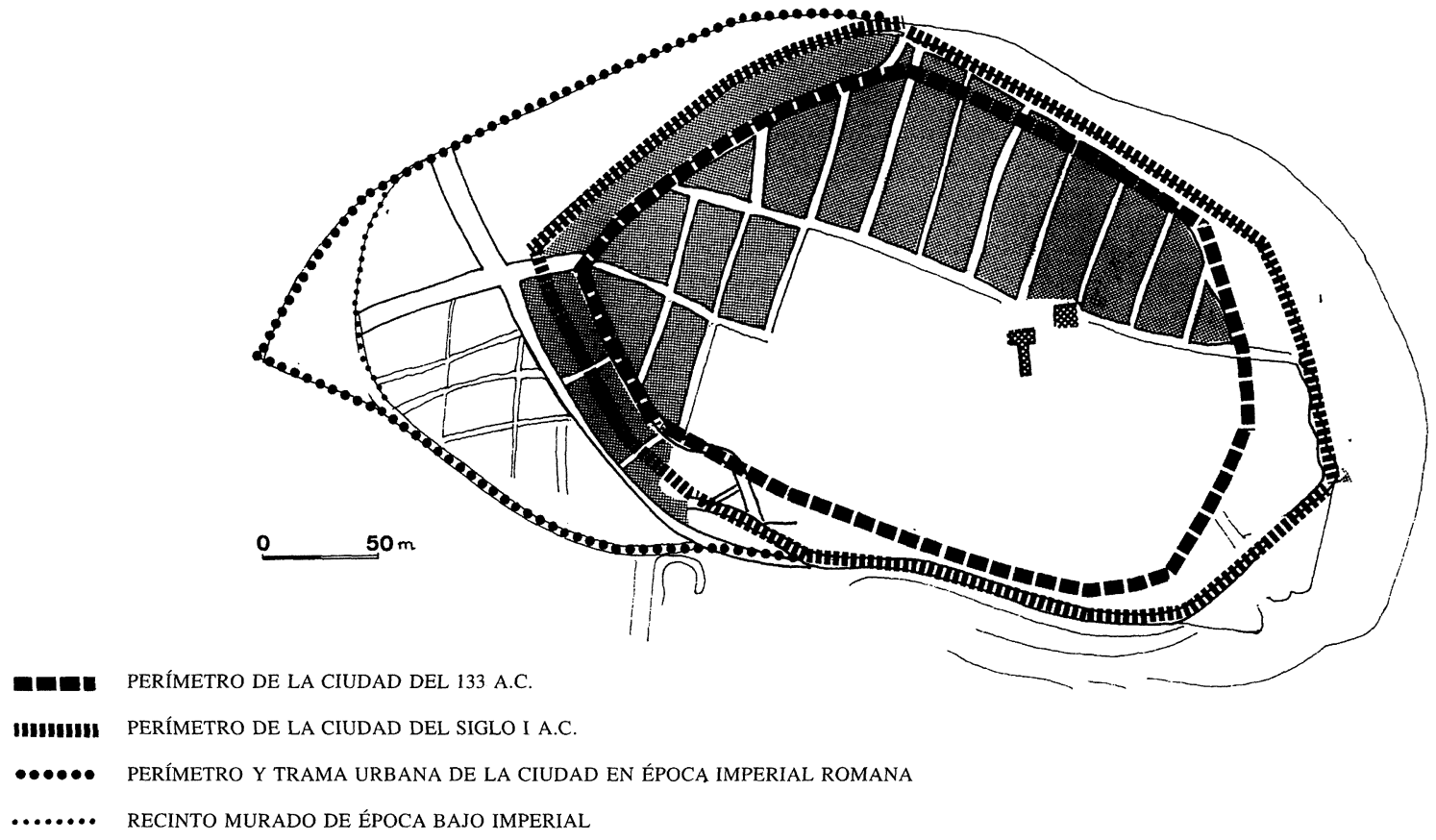

Fig. 10.-Delimitación de las diferentes ciudades. Escala 1/4.000.

les sobre la realidad arqueológica conocida distan mucho de alcanzar esta cifra.

La delimitación de esta ciudad sobre el plano de la ciudad conocida está determinada por la alineación semicircular más interna de la zona sur, correspondiente al cierre de la muralla en este lado. Esta alineación más interior queda reflejada en el lado oeste por las adaptaciones constructivas posteriores que sufrió esta zona, al ser ampliado el espacio habitable hasta una nueva línea defensiva. Como consecuencia de esta adaptación, la zona más exterior de las manzanas en este lugar acusa una ligera flexión a la altura de la anterior alineación. Por la zona Este es la fotografía aérea y los restos de excavación los que permiten señalar, con alguna duda, la línea de este perímetro, que continúa hacia el Norte, por donde cierra en forma semicircular, situándose en su zona central otra de las puertas de entrada.

El espacio habitado de la ciudad se debió reducir a esta zona alta, que ocupa una extensión de unas 7,6 ha $(7,2$ ha según Schulten); pero cabe pensar que esta línea defensiva no fue la única, ya que esta muralla superior deja sin controlar diferentes zonas de acceso, por lo que hay que admitir la existencia de otro u otros recintos murados en las laderas del cerro. La interpretación de más de un recinto murado está presente desde el primer plano que conocemos de Numancia, realizado por Loperráez (1788) en el siglo XVIII; también Schulten reparó en diferentes ali- neaciones, visibles en las laderas del cerro, identificándolas con líneas de defensa. La reanudación de los trabajos arqueológicos en Numancia, en el marco del Plan Director de la Junta de Castilla y León, conlleva la documentación del sistema defensivo de la ciudad, por lo que se están realizando cortes en la ladera Oeste del cerro para su localización.

Estos trabajos han revelado la gran alteración que ha sufrido esta ladera por su acondicionamiento para cultivo por medio de bancales, pero a su vez han documentado un derrumbe, cuyas características permiten relacionarlo con uno de estos muros defensivos, aunque su confirmación necesite de nuevas comprobaciones y una más amplia información. Si esta línea defensiva se confirma tendríamos que admitir zonas libres - desde el núcleo urbano superior hasta esta muralla- susceptibles de ocupación, en caso de necesidad, por las poblaciones del entorno o aquellos que se incorporaran a la defensa de la ciudad (caso de los segedenses), pero que nunca superaría la extensión de 4 ha.

La organización urbanística de esta ciudad es difícil de determinar, ya que poseemos escasos datos sobre ella, pero las referencias arqueológicas indican una disposición de los espacios habitados y de las casas de forma diferente a la urbanística conocida posteriormente. Esta diferencia se apoya en el análisis de la distribución de materiales arqueológicos que de este momento hemos realizado sobre el 
plano de Numancia, pudiendo comprobar cómo estos restos (diferentes tipos de fíbulas), que podrían remontarse al 133 a.C., no se insertan en las manzanas de casas conocidas, produciéndose su localización a lo largo de las calles, en las que se ha utilizado material echadizo anterior o se ha profundizado frecuentemente hasta el manto natural, descubriendo los restos de la ciudad más antigua; ello nos hace sospechar que estos espacios pudieron estar destinados en un trazado inicial a casas y estar indicando un plan urbanístico diferente del que ahora conocemos.

Arqueológicamente encontramos bases para documentar la existencia de esta ciudad en los hallazgos numismáticos, ya que los ejemplares más antiguos se fechan desde el 195 al 133 a.C., destacando como más abundante el numario romano republicano (22 ejemplares) y después el ibérico (destaca sekaisa con 5 ejemplares). La abundancia del numario republicano hay que relacionarla con la presen- cia de los ejércitos romanos en esta zona con motivo de las guerras celtibéricas (153 a 133 a.C.).

Por otro lado, unas doscientas fíbulas de diferentes tipos (Argente 1994:213-252): anulares (14 ejemplares, $6,5 \%)$, de pie vuelto rematado en disco ( 2 ejemplares, $0,89 \%$ ), de pie vuelto (66 ejemplares, $29,46 \%$ ), simétricas (20 ejemplares, $8,92 \%$ ), de torrecilla (23 ejemplares, $10,26 \%$ ), de pie zoomorfo en «S» (4 ejemplares, 1,78\%), de La Tène II ( 2 ejemplares, $0,89 \%$ ), de caballito (22 ejemplares, 9,82\%), otras zoomorfas (7 ejemplares, 3,12\%), de La Tène II-III A - Grupo IV de Cabré-Morán- (46 ejemplares, 20,53\%), de La Tène II-III B -Grupos VII-IX de Cabré-Morán- (14 ejemplares, 6,25\%) y de La Tène III - Grupo VIII de Cabré-Morán- (4 ejemplares, $1,78 \%$ ), aportan una mayor confluencia cronológica desde finales del siglo in al tercer cuarto del siglo II a.C. (Cuadrado 1972:99; Cabré y Morán 1979:5-26; Argente 1994:215-252), lo que apoya el marco cronológico propuesto (fig. 11). A este mo-

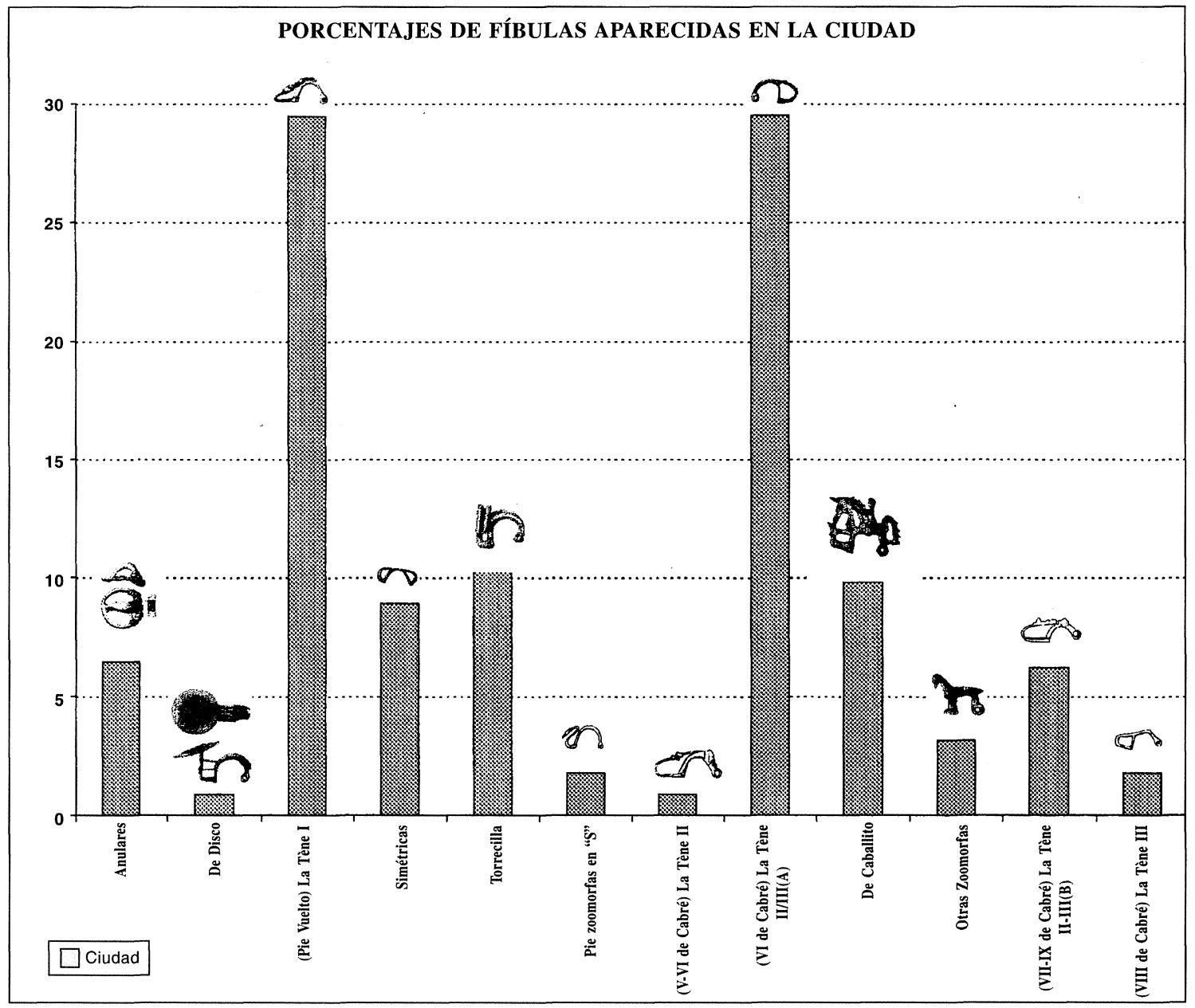

Fig. 11.-Representación de las fíbulas halladas en Numancia. 
mento deben corresponder las escasas armas halladas en la ciudad, que se reducen a algunas empuñaduras de espadas, tres puñales biglobulares, algunas puntas de lanza y cuchillos curvos, que armonizan bien con los tipos hallados en las necrópolis celtibéricas de este momento (Lorrio 1994:236-242) y en la de Numancia (Jimeno y Morales 1993 y 1994).

\section{RELACIÓN CIUDAD 133 A.C.-NECRÓPOLIS}

Los datos analizados aportan información suficiente para establecer la relación de la ciudad celtibérica del 133 a.C., mal documentada estratigráficamente, con esta necrópolis, que ofrecerá, a través del conocimiento mejor y más profundo de sus ajuares, bases de referencia para diferenciar la cultura material de esta ciudad.

\section{Relación espacial}

La necrópolis se sitúa en la ladera sur del poblado, en su zona media-baja. El poblado y la necrópolis como lugares de culto antiguos han quedado señalizados con sendas ermitas relacionadas con un poblamiento medieval, la de Los Mártires de Garray y San Antonio de Garrejo, en cuyas tierras se ubica la necrópolis.

La necrópolis era perfectamente visible desde los campamentos romanos de La Rasa, Dehesilla y Molino de Garrejo, pero estaba separada de éstos por los ríos Duero y Merdancho. La distancia desde la zona más alta del cerro (centro de la ciudad) es de unos $550 \mathrm{~m}$ y desde el límite de la ciudad de unos $300 \mathrm{~m}$, aunque un posible recinto murado, que limitaría la necrópolis por su zona alta, podría situarse a unos 35 a $40 \mathrm{~m}$. La necrópolis solamente sería visible desde este lugar adelantado, pero no desde el poblado (fig. 12).

El viento dominante es el de Norte, por lo que la necrópolis al situarse en la zona sur queda a resguardo y a su vez el viento dominante alejaría los humos de las cremaciones y los olores de la ciudad. El camino de acceso a la ciudad, que entraría por la puerta sur, pasa al lado de la necrópolis.

Un aspecto a destacar en la ubicación de las necrópolis celtibéricas, al igual que la de Numancia, es su relación con cauces de agua, como ya indicaba el Marqués de Cerralbo: "yo encuentro tantas estaciones porque excavo en las riberas de los ríos... como busco los yacimientos neolíticos en las cimas de los montes y las necrópolis ibéricas en las vegas, teniendo por indicadoras señales ríos, arroyos, fuen- tes o pozos de agua salada...» (Aguilera y Gamboa 1916:9). La necrópolis está entre dos ríos, el Duero, un poco más lejos, a poco más de $300 \mathrm{~m}$, y el Merdancho a unos $200 \mathrm{~m}$, que desemboca en el Duero a unos $400 \mathrm{~m}$ de la necrópolis. Creemos que en la elección del espacio para las necrópolis juega un aspecto importante la proximidad y disposición en relación a los cauces de agua disponibles en la zona (Jimeno y Heras 1996), que hay que relacionar con la importancia de este elemento en el ritual funerario. Como bien ha expuesto Sopeña (1987: 117-126), en las concepciones celtibéricas de ultratumba entran en conjunción tres elementos: aire, fuego y agua. La muerte se entiende como el cambio de estado entre la tierra y el cielo. El «tránsito» se realiza a través del aire, que aparece como vía migratoria por la que las almas ascienden a lo alto, transportadas por las aves, que aparecen como animales sagrados, psicopompos. Pero en este tránsito purificatorio del alma se conjugan tres elementos: aire (simbolizado en las aves), fuego (la pira funeraria) y agua, representada en los peces, que al igual que las aves, ascienden en su medio desde el fondo a la superficie; pero a su vez el pez es el devorador devorado y en diferentes mitologías, como las del ámbito latino, es también un animal psicopompo que transporta las almas hacia las islas de los Bienaventurados. La importancia de esta simbología acuática está bien representada en la cerámica numantina: un pez que intenta tragarse a un caballo, cuya cola termina en cabeza de toro; o el gran «Vaso de los toros», con tetrasqueles y ruedas solares en su cuerpo y bajo ellos un pez; dos hipocampos devoradores de peces ante la presencia de un gallo; o la representación conjunta de caballo, pájaro y pez; la alternancia radiada de peces y pájaros o peces solos en torno a un centro (Sopeña 1987:125 y 126).

\section{Relación cronológica}

Los tipos de fíbulas aparecidos en la necrópolis se corresponden plenamente con los conocidos en la ciudad (fig. 13). Tanto en la ciudad como en la necrópolis, los tipos mejor representados son los de pie vuelto, más abundantes en la necrópolis $(45,69 \%)$ que en la ciudad $(29,46 \%)$, seguidos de los anulares, igualmente más abundantes en la necrópolis $(29,80 \%)$ que en la ciudad $(6,5 \%)$; también las fíbulas de pie vuelto rematado en disco están mejor representadas, dentro de su poca frecuencia, en la necrópolis $(3,97 \%)$, que en la ciudad $(0,89 \%)$; pero los demás tipos son más abundantes en la ciu- 
TIPOS SIMILARES DE FÍBULAS APARECIDOS EN LA CIUDAD Y EN LA NECRÓPOLIS

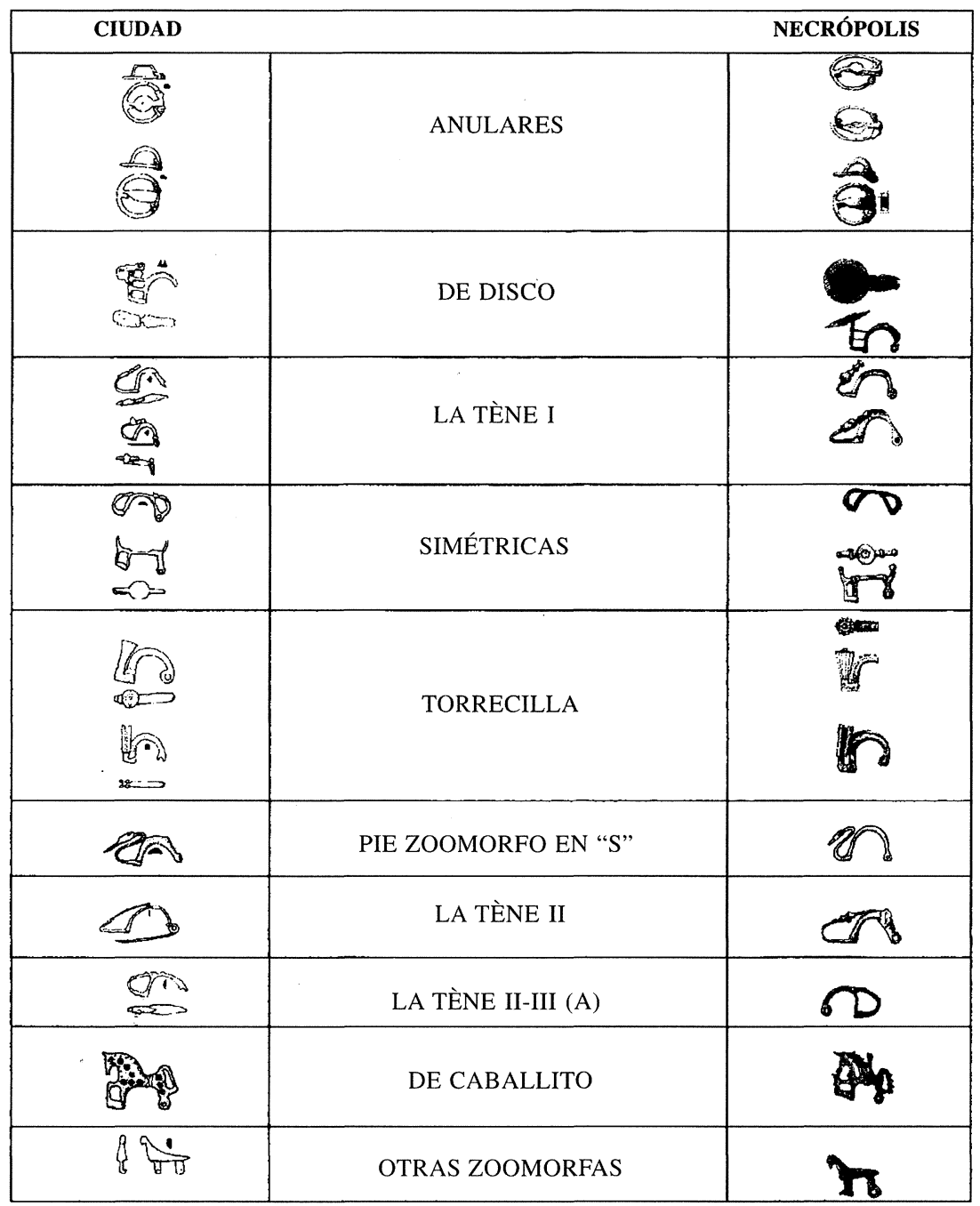

Fig. 13.-Similitud de los tipos de fíbulas de la necrópolis y la ciudad.

dad que en la necrópolis, destacando las fíbulas de La Tène II-III A (Grupo IV de Cabré-Morán) bien representadas en la ciudad $(20,53 \%)$ y escasas en la necrópolis $(3,97 \%)$, seguidas de las de torrecilla $(10,26 \%$ en la ciudad y $4,63 \%$ en la necrópolis $)$, de caballito $(9,82 \%$ en la ciudad y sólo $1,32 \%$ en la necrópolis), de las simétricas $(8,92 \%$ en la ciudad y $5,96 \%$ en la necrópolis), estando escasamente representadas en ambos los tipos zoomorfos diferentes del caballito $(3,12 \%$ en la ciudad y $1,32 \%$ en la necrópolis), las de pie zoomorfo en «S» $(1,78 \%$ en la ciudad y $0,6 \%$ en la necrópolis) y el denominado tipo clásico de La Tène II (Grupo V de Cabré-Mo- rán) escasamente representado en la ciudad y en la necrópolis $(0,89 \%$ y $1,98 \%$ respectivamente). No tenemos documentados hasta el momento en los conjuntos cerrados de la necrópolis los tipos de La Tène II-III B (Grupo VII y IX de Cabré-Morán) y los de La Tène III (Grupo VIII de Cabré-Morán), que en la ciudad alcanzan el $6,24 \%$ y el $1,78 \%$ respectivamente.

Las asociaciones de fíbulas documentadas en veinte tumbas de la necrópolis indican la coetaneidad de la mayoría de los tipos aparecidos; es decir, se da la confluencia de las fíbulas consideradas más antiguas, como las de pie vuelto vertical con rema- 


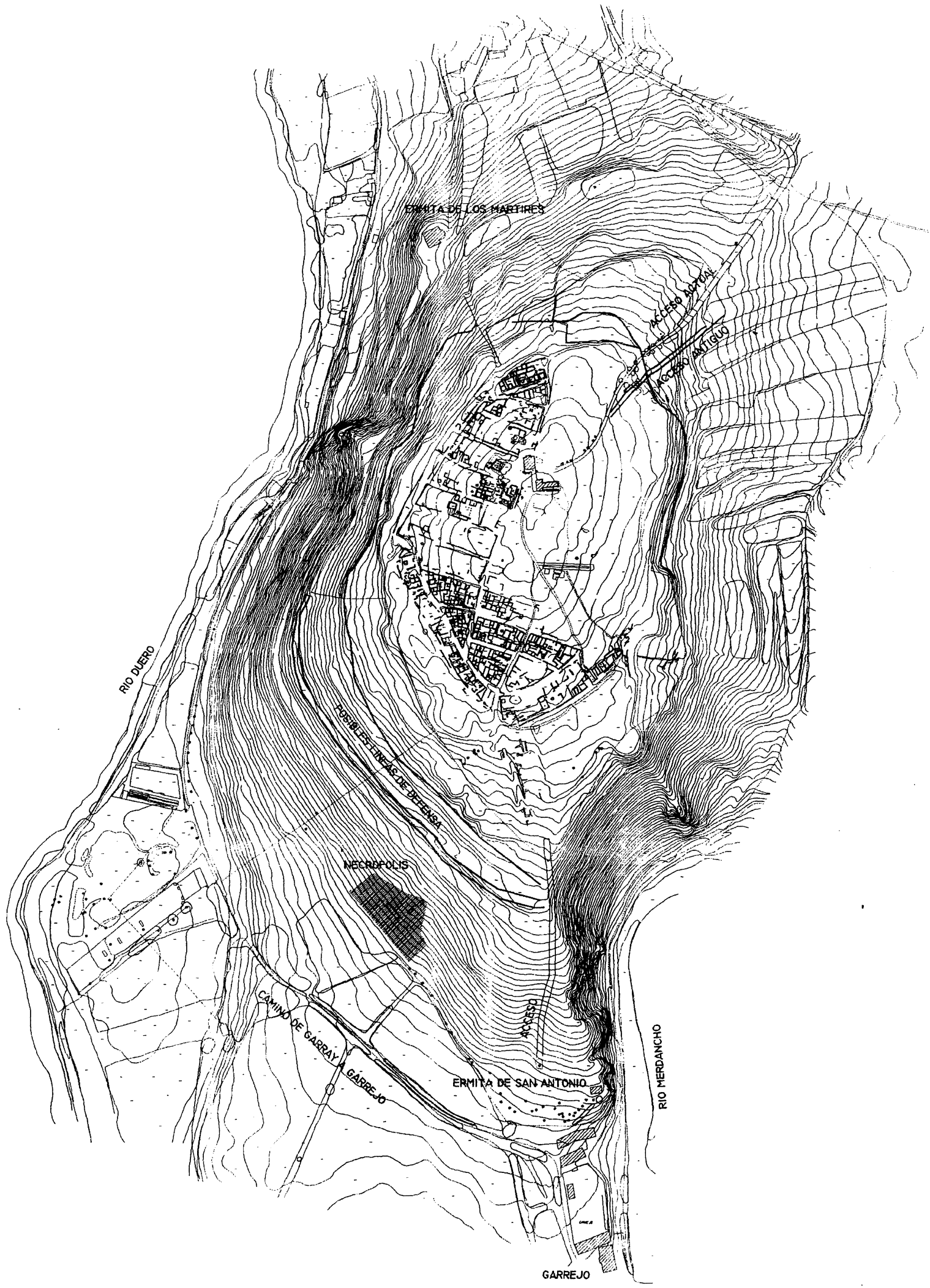

Fig. 12.-Relación necrópolis y ciudad. 
te en disco o cuadrado o las de pie vuelto de La Tène I, y las que inician su andadura, como las de La Téne II-II A -Grupo IV de Cabré-Morán (1979:10; 1982:20) — y II, que no superan cronológicamente el 100 a.C., como también se ha documentado en los castros de la Beturia céltica (Berrocal 1992: 137). Por otro lado, hay que señalar la ausencia de los tipos de La Tène III -Grupo VIII de Cabré-Morán (1979:10)—, característicos a lo largo del i siglo a.C. Todo ello permite situar cronológicamente esta necrópolis a lo largo del siglo II a.C., desde la fundación de Numancia a finales del siglo III o, quizás mejor, a principios del siglo il a.C., finalizando con la destrucción de la ciudad por Escipión en el 133 a.C. (fig. 14).

Este marco cronológico está avalado por la ausencia en la necrópolis de las cerámicas monócromas y polícromas, lo que indica también una cronología anterior al siglo i a.C., ya que, aunque desconocemos el tiempo que Numancia estuvo deshabitada después del 133 a.C., abundantes restos hallados indican una profusa ocupación a lo largo del siglo I a.C. y es precisamente a esta fase de la vida de la ciudad a la que corresponden sus producciones cerámicas monócromas y polícromas, que, como Wattenberg y trabajos posteriores han demostrado, deben ordenarse a lo largo del siglo I a.C., e incluso las especies polícromas alcanzarán los primeros momentos del Imperio (Wattenberg 1963a; Romero 1976; Arlegui 1986). Los tipos cerámicos de la necrópolis consisten en pequeños vasos oxidantes lisos o pueden llevar alguna línea pintada, lo que estaría indicando una cerámica anterior a las producciones generalizadas del siglo i a.C.

Otro argumento negativo es la ausencia en las tumbas de material romano, como la cerámica campaniense, bien conocida en la ciudad; así como de monedas, teniendo en cuenta que el mayor número

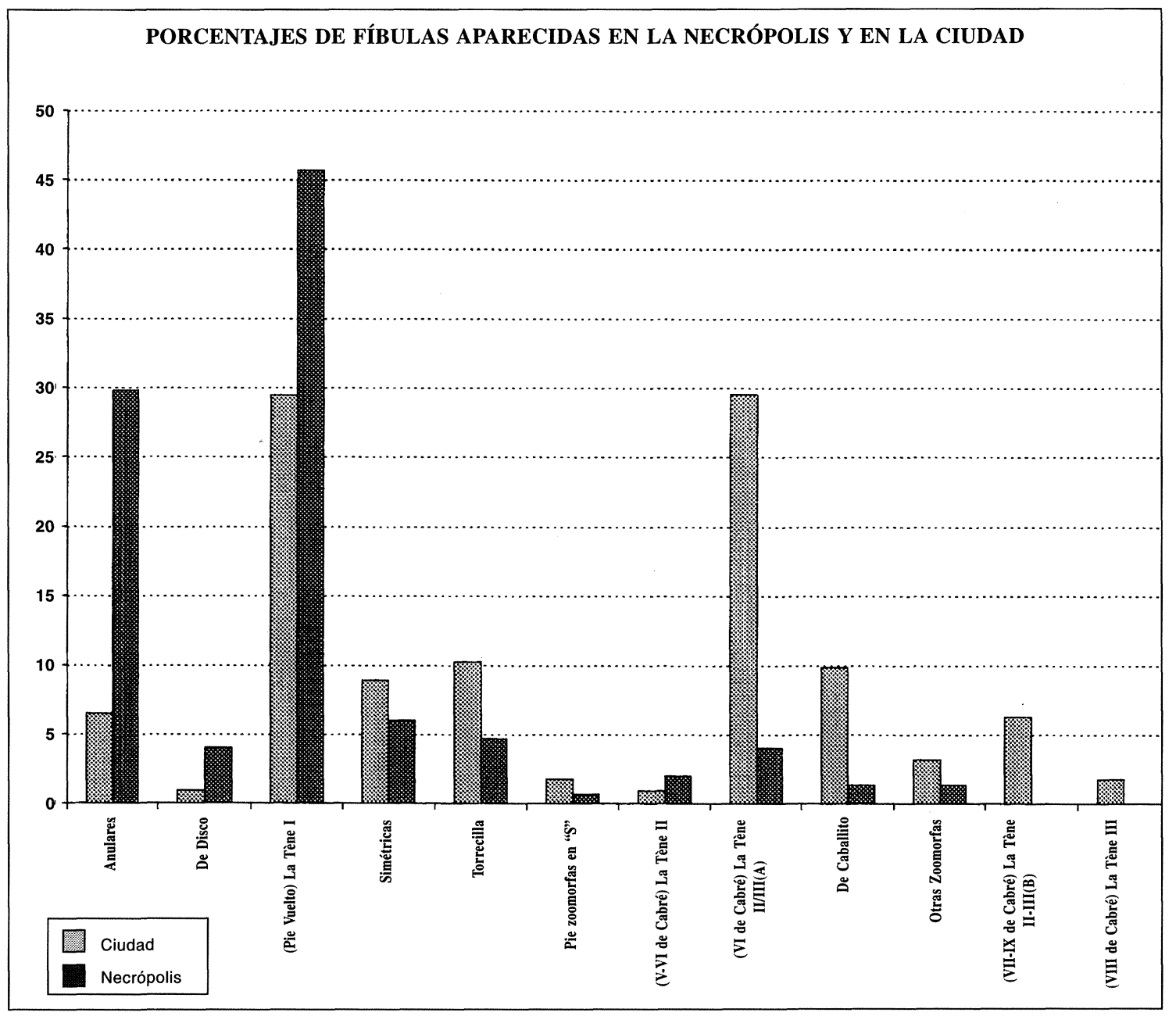

Fig. 14. - Representación conjunta de las fíbulas de la ciudad y la necrópolis. 
de las poco más de 300 monedas ibéricas, autónomas y romanas republicanas (Domínguez 1979; Romero y Martín 1992; Vidal 1993), se concentra entre el 133 y el 75 a.C., consecuencia del auge de las acuñaciones ibéricas, que conlleva un aumento de monedas y diversidad de cecas. Pero también estos datos reflejan el pulso y auge de la ciudad y por tanto la presencia de una ocupación importante en este momento del siglo i a.C., lo que indica una cierta continuidad de la ocupación de Numancia con posterioridad a su destrucción, negando el supuesto de que no se volvió a ocupar hasta época augustea. Esta ocupación prolongada a lo largo del siglo I a.C. se refleja en el incremento de monedas a partir del 27 a.C., procedentes de cecas del entorno del valle del Ebro más próximo a Numancia: Turiaso, Calagurris y Bilbilis (Jimeno y Martín 1995:187).

\section{BIBLIOGRAFÍA}

Aguilera y Gamboa, E. (1916): Las Necrópolis Ibéricas. Madrid.

Argente, J. L. (1994): Las fíbulas de la Edad del Hierro en la Meseta Oriental. Valoración tipológica, cronológica y cultural. Excavaciones Arqueológicas en España, 168, Madrid .

Argente, J. L.; Romero, F. (1990): «Fíbulas de doble prolongación, variante de disco, en la Meseta». Nvmantia, III, Junta de Castilla y León, Valladolid: 125-137.

ARLEGUi, M. A. (1986): Las cerámicas monócromas de Numancia. Memoria de Licenciatura. Universidad Complutense (inédita).

Berrocal Rangel, L. (1992): Los Pueblos célticos del Suroeste de la Península Ibérica. (Complutum, Extra 2).

CABré, E. (1990): «Espadas y puñales de las Necrópolis Celtibéricas». En F. Burillo (Coord.): II Simposio sobre los Celtíberos: Necrópolis Celtibéricas. Inst. Fernando El Católico, Zaragoza: 205-229.

CABré, E.; Morán, J. A. (1979): «Ensayo tipológico de las fíbulas con esquema de La Tène en la Meseta Hispánica». Boletín de la Asociación Española de Amigos de la Arqueología, 11-12: 5-26.

Cabré, E.; Morán, J. A. (1982): «Ensayo cronológico de las fíbulas con esquema de La Tène en la Meseta Hispánica». Boletín de la Asociación Española de Amigos de la Arqueología, 15: 427.

Cuadrado, E. (1972): «Las fíbulas anulares de Numancia». Crónica del Coloquio Conmemorativo del XXI Centenario de la Epopeya Numantina. Zaragoza: 91-99.

Domínguez, A. (1979): Cecas ibéricas del Valle del Ebro. Zaragoza.

García-Soto Mateos, E. (1990): «Las necrópolis de la Edad del Hierro en el Alto Valle del Duero». II Simposio sobre los celtíberos: Necrópolis Celtibéricas, Institución Fernando el Católico, Zaragoza: 13-38.

Gejvall, N.-G. (1980): «Cremaciones». En D. Brothwel y E. Higgs: Ciencia en Arqueología, Ed. F. C. E., Madrid: 482-493.

GonZÁlez SimanCAS, M. (1926): Las fortificaciones de Numancia. Excavaciones practicadas para su estudio. JSEA, núm. 74, Madrid.

IÑIGUEZ, M. (1916): Numancia y la medicina de la Antigua Iberia. Zaragoza.

JiMENO, A. (1994): «Numancia». En A. Rodero y M. Barril (Coord.): Leyenda y Arqueología de las Ciudades Prerromanas de la Península Ibérica. Museo Arqueológico Nacional, Madrid, Vol. II: 119-134.

Jimeno, A.; Arlegui, M. (1995): «El Poblamiento en el Alto Duero». En F. Burillo (coord.): Poblamiento Celtibérico. III Simposio sobre los Celtíberos. Institución «Fernando el Católico», Excma. Diputación Provincial de Zaragoza.

Jimeno, A.; FernándeZ, J. J.; Revilla. M. L. (1990): Numancia. Guía del Yacimiento. Asociación de Amigos del Museo Numantino. Soria.

Jimeno, A.; Heras, E. (1996): «Espacio de vivos y espacio de muertos». Complutum (e.p.).

Jimeno, A.; MARTín, A. (1995): «Estratigrafía y Numismática: Numancia y los Campamentos». En M. P. García-Bellido y R. M. Sobral: «La Moneda Hispánica. Ciudad y Territorio», Anejos de AEspA, XIV, C.S.I.C.: 179-190.

Jimeno, A.; Morales, F. (1993): «El poblamiento de la Edad del Hierro en el Alto Duero y la necrópolis de Numancia». Complutum, 4: 147-156.

Jimeno, A.; MoRales, F. (1994): «La localización de la necrópolis celtibérica de Numancia». Primer Congreso de Arqueología Peninsular (Actas III), Trabalhos de Antropología e Etnología, 34 (12): 249-258.

Jimeno, A.; TABernero, C. (1996): «Origen de Numancia y evolución urbana». Homenaje a $M$. Fernández-Miranda (e.p.).

Jimeno, A.; TrAncho, G. (1996): «Numancia». Investigación y Ciencia, núm. 232 (enero): 38-39.

Jimeno, A.; Trancho, G. et alii (1996): «Ritual y dieta alimenticia: la necrópolis celtibérica de Numancia». Nvmantia, 6 (e.p.). 
LOPERRÁEZ, J. (1788): Descripción Histórica del Obispado de Osma. t. II. Imprenta Real, Madrid.

LORRIO, A. (1994): «La evolución de la panoplia celtibérica». $M M, 35:$ 212-257.

MÉLIDA, J. R. (1922): Excursión a Numancia pasando por Soria. Edit. Ruiz Hermanos, Madrid.

Mélida, J. R.; Álvarez, M. A.; Gómez Santa Cruz, S.; TARACEnA, B. (1924): Ruinas de Numancia. Memoria descriptiva redactada conforme al plano que acompaña de las mismas. Memorias de la JSEA, núm. 61, Madrid.

MÉlidA, J. R.; TARACEnA, B. (1920, 1921 y 1923): Excavaciones de Numancia. Memorias de la JSEA, núms. 31, 36, 49.

Ortego, T. (1967): Guía de Numancia. Guías de Conjuntos Arqueológicos. Dirección General de Bellas Artes, Soria.

Reverte Coma, J. M. (1990): «Posibilidades de estudio antropológico y paleopatológico de las cremaciones». En F. Burillo: II Simposio sobre los Celtíberos: Necrópolis Celtibéricas. Inst. Fernando El Católico, Diputación de Zaragoza, Zaragoza: $329-335$.

Romero, F. (1976): Las cerámicas polícromas de Numancia. C.E. Sorianos, Valladolid.

Romero, F. (1991): Los Castros de la Edad del Hierro en el Norte de la provincia de Soria. Universidad de Valladolid.

Romero, F.; Martín, M. A. (1992): «Hallazgos monetarios ibéricos e hispanorromanos en $\mathrm{Nu}$ mancia». Actas del 2 Symposium de Arqueología Soriana. Diputación Provincial de Soria, Soria: 606-610.
SChÜLE, W. (1969): Die Meseta-Kulturen der Iberischen Halbinsel. Madrider Forschungen, 3, Berlin.

Schulten, A. (1914-1931): Nvmantia. Die Ergebnisse der Ausgrabungen 1905-1912. München, 4 vols.

Schulten, A. (1945): Historia de Numancia. Ed. Barna, Barcelona.

Schulten, A. (1957): Las Guerras de 154 a 72 a.C., Fontes Hispaniae Antiquae, fasc. IV, Universidad de Barcelona, Bosch, Barcelona.

Sopeña, G. (1987): Dioses, Ética y Ritos. Universidad de Zaragoza

Taracena, B. (1941): Carta Arqueológica de España. Soria. Instituto Diego Velázquez, C.S.I.C., Madrid.

Taracena, B. (1943): «Cabezas-Trofeo en la España Céltica». AEspA, 51: 157-171.

Vidal BARdán, J. M. (1993): Hallazgos numismáticos de la Meseta Oriental (Ciclo Colonial). Tesis Doctoral de la Universidad Complutense (inédita).

VV.AA. (1912): Excavaciones de Numancia. Memoria presentada al Ministerio de Instrucción Pública y Bellas Artes por la Comisión ejecutiva. Madrid.

W ATTENBERG, F. (1960): «Los problemas de la Cultura Celtibérica». Primer Symposium de Prehistoria de la Península Ibérica, Pamplona: 151-177.

WATTENBERG, F. (1963a): Las cerámicas indígenas de Numancia. Bibliotheca Praehistorica Hispana, vol. IV, Madrid.

W ATTENBERG, F. (1963b): Informe sobre los trabajos realizados en las Excavaciones de Numancia. NAH, VII: 132-142. 